\title{
Association of Pregnancy-Related Factors and Cardiovascular Disease in the Long Term
}

\author{
Indrani Garre ${ }^{1}$ Lalita Nemani ${ }^{2}$ Raju Nallagasu ${ }^{3}$ \\ ${ }^{1}$ Department of Cardiology, Nizam's Institute of Medical Sciences \\ (NIMS), Punjagutta, Hyderabad, India \\ 2Department of Cardiology, Nizam's Institute of Medical Sciences \\ (NIMS), Punjagutta, Hyderabad, India \\ ${ }^{3}$ Department of Nephrology, Nizam's Institute of Medical Sciences \\ (NIMS), Punjagutta, Hyderabad, India \\ Indian J Cardiovasc Dis Women-WINCARS 2018;3:184-188
}

\begin{abstract}
Address for correspondence Indrani Garre, PhD Student, Department of Cardiology, Nizam's Institute of Medical Sciences (NIMS), Punjagutta, Hyderabad, 500082, Telangana, India (e-mail: indrani.garre@gmail.com).
\end{abstract}

\begin{abstract}
Aim To observe the association of pregnancy-related factors on the incidence of cardiovascular disease (CVD).

Introduction CVD is one of the leading causes of death in women. It really emphasizes the need for early recognition of cardiovascular risk in women. Heart disease in women poses a major challenge in that the first events are more likely to be fatal. Pregnancy itself predicts cardiovascular disease in later life and is a screening test for CVD.

Methods Total 136 female patients from the outpatient clinic, as well as patients of our hospital, were included in our retrospective single-center study. Along with demographic data and details of risk factors, the reproductive history of all patients such as age at first pregnancy, number of children, any hormonal therapy, and mode and place of delivery were noted. Pregnancy-related data, such as the history of hypertension, diabetes, abortion, pregnancy loss; preterm delivery; and the weight of the newborn were taken into consideration. We excluded unmarried and nulliparous women.

Results The study population comprised 136 female patients. There were 69 (50.74\%) in group 1 (coronary artery disease [CAD] group) and 67 (49.36\%) in group 2 (non-CAD group). Mean age of patients at enrollment was $53.2 \pm 12.52$ years. Twenty-seven (19.8\%) patients fell under lost pregnancy or child category, and abortions and preterm delivery were faced in 26 (19.1\%). Seventy-one (52.2\%) patients attained menopause whereas hysterectomy was done in 35 (25.7\%). The average age of hysterectomy was $38.37 \pm 8.50$ years, and that for menopause was $46.78 \pm 5.04$ years. During pregnancy, the history of hypertension was given only in $4(3 \%)$, diabetes was in given none, and history of a low birth weight of the newborn was given in $3(2.2 \%)$ women. The univariate analysis was done to see the statistical significance of mainly pregnancy factors on long-term cardiac outcomes along with risk factors. Generally, hypertension

\section{Keywords}

- pregnancy-related factors

- cardiovascular disease

- coronary artery disease $(p=0.01)$ and diabetes $(p=0.01)$ had significance with cardiac outcomes. In spite of these, the history of a lost pregnancy/child and pregnancy complications both have shown near significance, that is, $p=0.06$.

Conclusion Our study suggests an impact of pregnancy loss irrespective of the etiology on the future cardiac outcomes as along with predominant impact factors of hypertension and diabetes.
\end{abstract}

received

October 9, 2018

accepted after revision

November 6, 2018
Dol https://doi.org/

10.1055/s-0038-1677054
(C)2018 Women in Cardiology and Related Sciences
License terms

(1) (1) $\Theta \circledast$ 


\section{Introduction}

Cardiovascular disease (CVD) is one of the major causes of death in women. Heart disease in women poses a major challenge in that the first events are more likely to be fatal. This emphasizes the need for early recognition of cardiovascular (CV) risk in women. Roberts and Hubel highlight that pregnancy history is hugely significant in the $\mathrm{CV}$ risk assessment in women. ${ }^{1}$ The pregnancy disorder-preeclampsia that occurs in about $7 \%$ of pregnancies-has a well-established relationship with future CVD. ${ }^{2}$

Pregnancy is a normal physiologic state in a woman's life. A complicated pregnancy is a harbinger of future CVD. The complications may be limited to the pregnancy period but leave permanent vascular and metabolic damage, which are predictive of CVD in later life. Hypertension in pregnancy is an established risk factor for coronary heart disease (CHD) and stroke in women. A sibling history of hypertension in pregnancy may be a novel familial risk factor for future hypertension. ${ }^{3}$ Gestational diabetes, preterm delivery, and assisted reproductive procedures also have a bearing on the future $\mathrm{CV}$ risk of a woman., ${ }^{4,5}$ This awareness in the medical community, especially obstetricians, physicians, and cardiologists, would play a crucial role in detecting these complications and monitoring them appropriately. ${ }^{6,7}$

Pregnancy itself soothsays the CVD in later life. Pregnancy can be a screening test for CVD. Obtaining maximum information about pregnancy and exploit on that will help prevent CV events in women's in later life. Based the degree of risk, CVD prevention in women should guide the assessment and management strategies.

\section{Materials and Methods}

This is a retrospective single-center study including 136 female patients of the outpatient clinic as well as patients of our hospital. The reproductive history of all patients such as age at first pregnancy, number of children, any hormonal therapy, and mode and place of delivery were noted. Pregnancy-related data, such as history of hypertension, diabetes, abortion, pregnancy loss; preterm delivery; and the weight of the newborn were taken into consideration. Laboratory tests and cardiac history were collected from their recent medical records. All patients underwent electrocardiogram and echocardiography to evaluate their cardiac status and exercise stress testing and coronary angiogram for confirmation whenever the clinical scenario demanded. We excluded unmarried and nulliparous women.

This study population was divided into coronary artery disease (CAD) patients (group 1) and non-CAD patients (group 2) based on the final diagnosis.

The statistical analysis was done with Minitab version 17 (Minitab, Ltd.). The univariate analysis through chi-square test was used for comparison between the two groups. The statistical significance $(p<0.05)$ was taken as significant.

\section{Results}

This study population comprised 136 female patients. There were 69 (50.74\%) in group 1 (CAD group) and 67 (49.36\%) in group 2 (non-CAD group). Mean age of patients at enrollment was $53.2 \pm 12.52$ years. The demographic data of the entire cohort are mentioned in $\boldsymbol{-}$ Table $\mathbf{1}$.

\section{Reproductive Risk Factors}

The age of menarche was $12.95 \pm 1.51$ years, and the average number of children per patient was $3.13 \pm 1.58$. The age at first pregnancy was $19.04 \pm 3.99$ years. Breast-feeding duration was $1.69 \pm 0.97$ years. About 117 (86.02\%) women had a normal vaginal delivery. The majority had an institutional delivery, that is, $83(61.02 \%)$ patients. Twenty-seven (19.8\%) fell under lost pregnancy or child category, and abortions and preterm delivery were faced in 26 (19.1\%). Seventy-one (52.2\%) patients attained menopause whereas hysterectomy was done in 35 (25.7\%). Average age of hysterectomy was $38.37 \pm 8.50$ years and menopause was $46.78 \pm 5.04$ years.

During pregnancy, the history of hypertension was given only in $4(3 \%)$, diabetes was given in none, and history of low birth weight of the newborn was given in $3(2.2 \%)$ women.

The biochemical investigations of the study population are mentioned in - Table $\mathbf{2}$. The lipid profile was done in only 79 patients, of whom 12 had hyperlipidemia.

The univariate analysis was done to see the statistical significance of mainly pregnancy factors on long-term cardiac outcomes along with risk factors. Generally, hypertension $(p=0.01)$ and diabetes $(p=0.01)$ had significance with cardiac outcomes. In spite of these, the history of lost pregnancy/child and pregnancy complications both have shown near significance, that is, $p=0.06$. Details are mentioned in $\boldsymbol{-}$ Table $\mathbf{3}$ and $\boldsymbol{\bullet}$ Fig. $\mathbf{1}$.

Table 1 Descriptive statistics of study population

\begin{tabular}{|l|l|}
\hline Variable & Mean \pm SD \\
\hline Age (y) & $53.2 \pm 12.52$ \\
\hline Hypertensives (\%) & $87(63.9 \%)$ \\
\hline Hypertension duration (y) & $7.08 \pm 6.99$ \\
\hline Diabetics (\%) & $66(48.53 \%)$ \\
\hline Diabetics duration (y) & $8.12 \pm 8.14$ \\
\hline Family history (\%) & $12(8.82 \%)$ \\
\hline Other risk factors (\%) & $54(39.51 \%)$ \\
\hline CAD patients (\%) & $69(50.74 \%)$ \\
\hline Height $(\mathrm{cm})$ & $157.36 \pm 5.2$ \\
\hline Weight $(\mathrm{kg})$ & $65.09 \pm 11.4$ \\
\hline Systolic blood pressure $(\mathrm{mm} \mathrm{Hg})$ & $128.12 \pm 24.59$ \\
\hline Diastolic blood pressure $(\mathrm{mm} \mathrm{Hg})$ & $81.89 \pm 10.02$ \\
\hline Pulse rate (beats/min) & $81.64 \pm 12.21$ \\
\hline
\end{tabular}

Abbreviations: CAD, coronary artery disease; SD, standard deviation. 
Table 2 Descriptive statistics of laboratory parameters

\begin{tabular}{|c|c|}
\hline Variable & Mean \pm SD \\
\hline Hemoglobin (g \%) & $11.58 \pm 1.79$ \\
\hline Blood urea (mg/dL) & $28.29 \pm 12.80$ \\
\hline Serum creatinine (mg/dL) & $0.94 \pm 0.56$ \\
\hline Random blood sugar (mg/dL) & $132.53 \pm 69.75$ \\
\hline $\mathrm{TC}(\mathrm{mg} / \mathrm{dL})$ & $170.06 \pm 46.41$ \\
\hline $\mathrm{HDL}(\mathrm{mg} / \mathrm{dL})$ & $52.86 \pm 23.54$ \\
\hline $\mathrm{LDL}(\mathrm{mg} / \mathrm{dL})$ & $96.63 \pm 47.07$ \\
\hline $\operatorname{VLDL}(\mathrm{mg} / \mathrm{dL})$ & $23.91 \pm 9.12$ \\
\hline Triglycerides (mg/dL) & $125.6 \pm 73.7$ \\
\hline TC/HDL ratio & $4.12 \pm 2.12$ \\
\hline Sodium (NA) (mEq/L) & $137.03 \pm 19.99$ \\
\hline Potassium (K) (mEq/L) & $25.1 \pm 120.6$ \\
\hline Chloride $(\mathrm{Cl})(\mathrm{mEq} / \mathrm{L})$ & $100.23 \pm 11.01$ \\
\hline T3 (ng/dL) & $1.85 \pm 1.83$ \\
\hline T4 (ng/dL) & $11.86 \pm 15.78$ \\
\hline TSH (ng/dL) & $4.58 \pm 10.09$ \\
\hline $\mathrm{HBA}_{1 \mathrm{C}}(\%)$ & $7.44 \pm 1.95$ \\
\hline $\mathrm{hsCRP}(\mathrm{mg} / \mathrm{L})$ & $4.96 \pm 4.01$ \\
\hline Vitamin D (ng/mL) & $19.33 \pm 6.41$ \\
\hline
\end{tabular}

Abbreviations: CAD, coronary artery disease; $\mathrm{HDL}$, high-density lipoprotein; hsCRP, high-sensitivity C-reactive protein; LDL, low-density lipoprotein; SD, standard deviation; TC, total cholesterol; TSH, thyroid-stimulating hormone; VLDL, very low-density lipoprotein.

\section{Discussion}

There is an influence of several factors on women's risk for CAD. Despite traditional CAD risk factors, there are several risk factors exclusive and foremost to women who also confer an increased CV risk. The effect and complexity of biological, physiologic, and hormonal factors on women with CAD risk cannot be understood or explained with simply knowledge of heart diseases in men. Through this study the authors would like to highlight the women-specific predominant risk factors for the burden of CAD.

The well-known facts about pregnancy-related risk factors are the increased $\mathrm{CV}$ risk associated with gestational diabetes mellitus (GDM), ${ }^{8-10}$ gestational hypertension, preeclampsia, and eclampsia. ${ }^{11-15}$ Less well-known facts are the association of CAD with other pregnancy-related factors such as preterm delivery, ${ }^{16-18}$ spontaneous pregnancy loss, and history of stillbirth. Recurrent miscarriages play a role as the future risk for CAD/CHD. Meta-analysis of nearly 10 studies has shown it to be associated with higher likelihood of developing future CHD. ${ }^{19,20}$ As per the literature, > 3.5 times higher risk of myocardial infarction (MI) was associated with history of stillbirth. The recurrent miscarriage (more than three occurrences) was associated with nearly nine times higher risk of MI. ${ }^{21}$

In our study also, CAD was associated significantly with lost pregnancy and/or child, and abortions and preterm delivery were $p=0.06$.
Table 3 Comparison of outcomes with pregnancy parameters and risk factors

\begin{tabular}{|c|c|c|c|}
\hline Variable & $\begin{array}{l}\text { Group A: } \\
\text { Cardiac } \\
(n=69)\end{array}$ & $\begin{array}{l}\text { Group B: } \\
\text { Noncardiac } \\
(n=67)\end{array}$ & $p$ Value \\
\hline Hypertensives & $51(73.9 \%)$ & 36 (53.7\%) & \multirow[t]{2}{*}{0.01} \\
\hline Nonhypertensives & $18(26.1 \%)$ & 31 (46.3\%) & \\
\hline Diabetics & 39 (56.5\%) & $24(35.8 \%)$ & \multirow[t]{2}{*}{0.01} \\
\hline Nondiabetics & $30(43.5 \%)$ & 43 (64.2\%) & \\
\hline $\begin{array}{l}\text { Other risk } \\
\text { factors-present }\end{array}$ & $30(43.5 \%)$ & $24(35.8 \%)$ & \multirow[t]{2}{*}{0.36} \\
\hline $\begin{array}{l}\text { Other risk } \\
\text { factors-absent }\end{array}$ & 39 (56.5\%) & $43(64.2 \%)$ & \\
\hline $\begin{array}{l}\text { Family } \\
\text { history-present }\end{array}$ & $6(8.7 \%)$ & $6(8.9 \%)$ & \multirow[t]{2}{*}{0.95} \\
\hline $\begin{array}{l}\text { Family } \\
\text { history_absent }\end{array}$ & $63(91.3 \%)$ & 61 (91.1\%) & \\
\hline $\begin{array}{l}\text { Any hormone } \\
\text { intake-yes }\end{array}$ & $9(13.04 \%)$ & $7(10.4 \%)$ & \multirow[t]{2}{*}{0.63} \\
\hline $\begin{array}{l}\text { Any hormone } \\
\text { intake-no }\end{array}$ & $\begin{array}{l}60 \\
(86.96 \%)\end{array}$ & 60 (89.6\%) & \\
\hline $\begin{array}{l}\text { Lost pregnancy/ } \\
\text { child-yes }\end{array}$ & $18(26.1 \%)$ & $9(13.4 \%)$ & \multirow[t]{2}{*}{0.06} \\
\hline $\begin{array}{l}\text { Lost pregnancy/ } \\
\text { child-no }\end{array}$ & $51(73.9 \%)$ & $58(86.6 \%)$ & \\
\hline Normal delivery & $60(86.9 \%)$ & $57(85.1 \%)$ & \multirow[t]{2}{*}{0.75} \\
\hline $\begin{array}{l}\text { Cesarean section } \\
\text { (C-section) }\end{array}$ & $9(13.1 \%)$ & 10 (14.9\%) & \\
\hline Home delivery & $24(34.8 \%)$ & $30(44.8 \%)$ & \multirow[t]{2}{*}{0.23} \\
\hline Hospital delivery & 45 (65.2\%) & 37 (55.2\%) & \\
\hline $\begin{array}{l}\text { Pregnancy } \\
\text { complications-yes }\end{array}$ & $17(24.6 \%)$ & $9(13.4 \%)$ & \multirow[t]{2}{*}{0.06} \\
\hline $\begin{array}{l}\text { Pregnancy } \\
\text { complications-no }\end{array}$ & $52(75.4 \%)$ & $58(86.6 \%)$ & \\
\hline
\end{tabular}

These women-specific risk factors are not only limited to above, but following factors also play a role in future CVD. However, these have not been analyzed in our study as the study was focused on the pregnancy-related factors only. Premature menopause predisposes to CAD; however, menopausal hormone therapy for the primary or secondary prevention of CVD was not recommended. ${ }^{22,23}$ Psychosocial factors have additionally been related to $\mathrm{CHD} .{ }^{24}$ In every age group compared with men, the more women have 


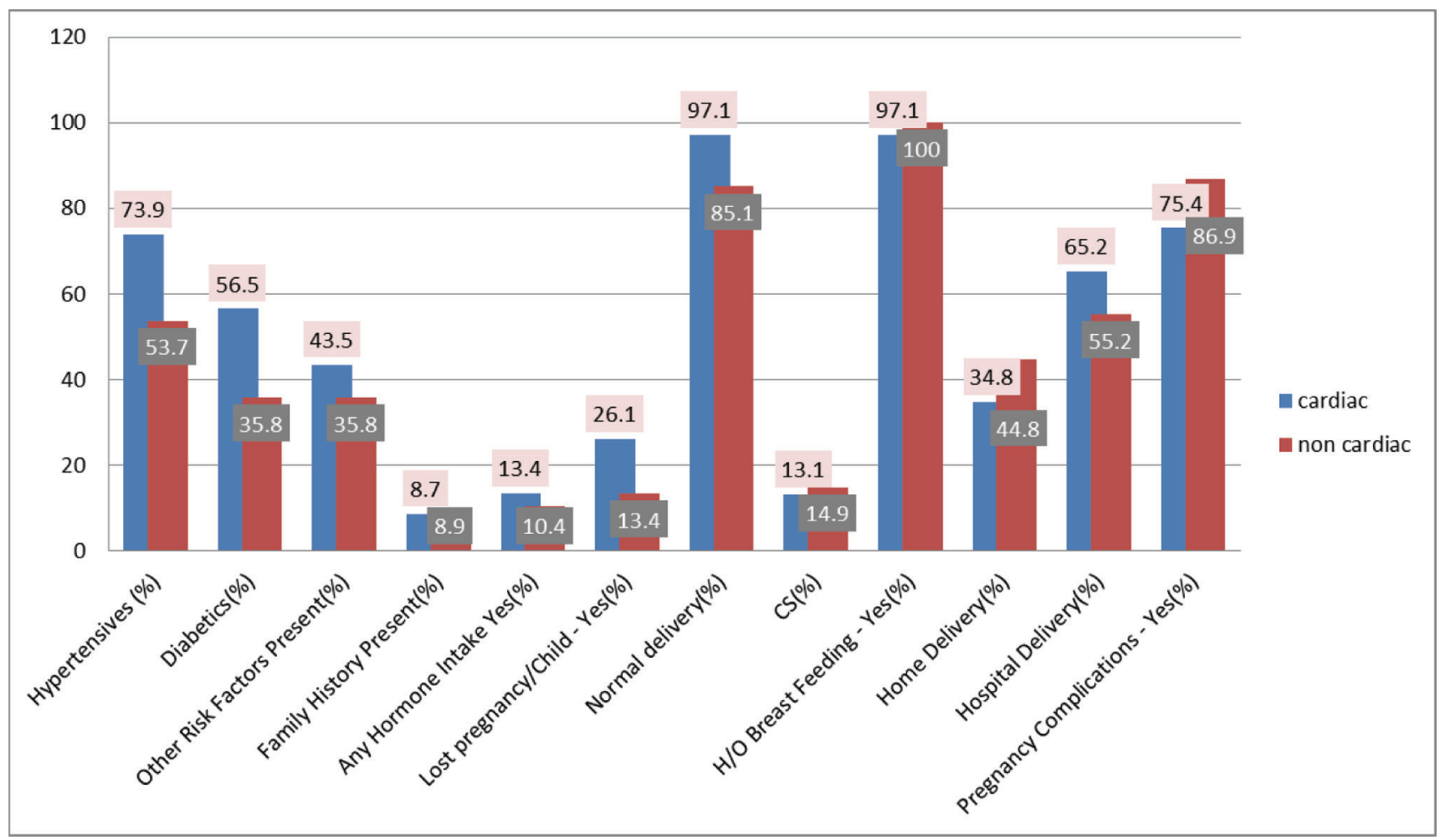

Fig. 1 Comparison between groups A and B.

depression and the depression rate was nearly twice, ${ }^{25-27}$ and studies have shown that symptoms of depression are directly associated with CHD risk. ${ }^{28}$ According to the American Heart Association/American College of Cardiology Foundation recommendations, the treatment of depression has not been shown to improve $\mathrm{CV}$ outcomes. ${ }^{29}$

The risk assessment for women with CAD should involve history, clinical examination, and laboratory testing. The direct preventive strategies to reduce CAD in asymptomatic women should develop through risk assessment calculators. The increased awareness of women-specific risk factors for CAD has led to educating women so that we can decrease the future cardiac events.

The reproductive years are an ideal time to evaluate preclinical CVD risk and launch approaches to prevent or delay the onset of disease in women. Therefore, the early detection of risk unmasked by pregnancy offers a great opportunity to improve the health of women, but not yet tested. Further, implements are required to translate this potential into meaningful improvements in the health of women. The contribution of a tool to obtain valid pregnancy history information via maternal recall is an important step in this direction.

There is a requirement to update risk factors for CVD in women by including the pregnancy-related events. Understanding the mechanisms that link pregnancy loss and CVD and how to include information of pregnancy loss (and other adverse pregnancy events) for CVD assessment is still required to be determined.

\section{Limitation}

As it was a retrospective study, patients were not able to recollect the details of pregnancy complications such as gestational hypertension, diabetics, preterm delivery, and low birth. This was a small population study and requires confirming the results in larger population.

\section{Conclusion}

Our study suggests that there is an impact of pregnancy loss irrespective of the etiology on the future cardiac outcomes as along with predominant impact factors of hypertension and diabetes.

\section{References}

1 Roberts JM, Hubel CA. Pregnancy: a screening test for later life cardiovascular disease. Women's Health Issues 2010;20(5):304-307

2 Duckitt K, Harrington D. Risk factors for pre-eclampsia at antenatal booking: systematic review of controlled studies. BM] 2005;330(7491):565 https://www.ncbi.nlm.nih.gov/pmc/ articles/PMC554027/Retrieved December 30, 2016

3 Weissgerber TL, Turner ST, Mosley TH Jr, et al. Hypertension in pregnancy and future cardiovascular event risk in siblings. J Am Soc Nephrol 2016;27(3):894-902

4 Harrison BJ, Hilton TN, Rivière RN, Ferraro ZM, Deonandan R, Walker MC. Advanced maternal age: ethical and medical considerations for assisted reproductive technology. Int J Womens Health 2017;9:561-570 
5 Burlina S, Dalfrà MG, Chilelli NC, Lapolla A. Gestational diabetes mellitus and future cardiovascular risk: an update. Int J Endocrinol 2016:2070926. http://dx.doi.org/10.1155/2016/2070926

6 Chhabra ST, Bali R, Kaur T, et al. Is pregnancy a risk factor for future cardiovascular events? Ind J Car Dis Wom 2017;2(3):56-62

7 Catov Janet M. Pregnancy as a window to cardiovascular disease risk: how will we know? J Womens Health (Larchmt) 2015;24(9):691-692

8 Bellamy L, Casas JP, Hingorani AD, Williams D. Type 2 diabetes mellitus after gestational diabetes: a systematic review and meta-analysis. Lancet 2009;373(9677):1773-1779

9 Carr DB, Utzschneider KM, Hull RL, et al. Gestational diabetes mellitus increases the risk of cardiovascular disease in women with a family history of type 2 diabetes. Diabetes Care 2006;29(9):2078-2083

10 Bentley-Lewis R. Late cardiovascular consequences of gestational diabetes mellitus. Semin Reprod Med 2009; 27(4):322-329

11 American College of Obstetricians and Gynecologists; Task Force on Hypertension in Pregnancy. Hypertension in pregnancy. Report of the American College of Obstetricians and Gynecologists' Task Force on Hypertension in Pregnancy. Obstet Gynecol 2013;122(5):1122-1131

12 Männistö T, Mendola P, Vääräsmäki $\mathrm{M}$, et al. Elevated blood pressure in pregnancy and subsequent chronic disease risk. Circulation 2013;127(6):681-690

13 Lykke JA, Langhoff-Roos J, Sibai BM, Funai EF, Triche EW, Paidas MJ. Hypertensive pregnancy disorders and subsequent cardiovascular morbidity and type 2 diabetes mellitus in the mother. Hypertension 2009;53(6):944-951

14 Marín R, Gorostidi M, Portal CG, Sánchez M, Sánchez E, Alvarez J. Long-term prognosis of hypertension in pregnancy. Hypertens Pregnancy 2000;19(2):199-209

15 Bellamy L, Casas JP, Hingorani AD, Williams DJ. Pre-eclampsia and risk of cardiovascular disease and cancer in later life: systematic review and meta-analysis. BMJ 2007;335(7627):974

16 Nardi O, Zureik M, Courbon D, Ducimetière P, Clavel-Chapelon F. Preterm delivery of a first child and subsequent mothers' risk of ischaemic heart disease: a nested case-control study. Eur J Cardiovasc Prev Rehabil 2006;13(2):281-283

17 Catov JM, Wu CS, Olsen J, Sutton-Tyrrell K, Li J, Nohr EA. Early or recurrent preterm birth and maternal cardiovascular disease risk. Ann Epidemiol 2010;20(8):604-609

18 Bukowski R, Davis KE, Wilson PW. Delivery of a small for gestational age infant and greater maternal risk of ischemic heart disease. PLoS One 2012;7(3):e33047
19 Oliver-Williams CT, Heydon EE, Smith GC, Wood AM. Miscarriage and future maternal cardiovascular disease: a systematic review and meta-analysis. Heart 2013;99(22):1636-1644

20 Ranthe MF, Boyd HA. Miscarriage and cardiovascular disease. Heart 2015;101(24):1933-1934

21 Kharazmi E, Dossus L, Rohrmann S, Kaaks R. Pregnancy loss and risk of cardiovascular disease: a prospective population-based cohort study (EPIC-Heidelberg) Heart 2011;97(1):49-54

22 Hulley S, Grady D, Bush T, et al. Randomized trial of estrogen plus progestin for secondary prevention of coronary heart disease in postmenopausal women. Heart and Estrogen/ progestin Replacement Study (HERS) Research Group. JAMA 1998;280(7):605-613

23 Rossouw JE, Anderson GL, Prentice RL, et al; Writing Group for the Women's Health Initiative Investigators. Risks and benefits of estrogen plus progestin in healthy postmenopausal women: principal results from the Women's Health Initiative randomized controlled trial. JAMA 2002;288(3):321-333

24 Varghese T, Hayek SS, Shekiladze N, Schultz WM, Wenger NK. Psychosocial risk factors related to ischemic heart disease in women. Curr Pharm Des 2016;22(25):3853-3870

25 Center for Behavioral Health Statistics and Quality. Behavioral health trends in the United States: results from the 2014 National Survey on Drug Use and Health (HHS Publication No. SMA 15-4927, NSDUH Series H-50). 2015. http://www.samhsa.gov/data/sites/default/files/NSDUH-FRR1-2014/NSDUH FRR1-2014.htm. Accessed November 27, 2016

26 Kessler RC, Berglund P, Demler O, et al; National Comorbidity Survey Replication. The epidemiology of major depressive disorder: results from the National Comorbidity Survey Replication (NCS-R) JAMA 2003;289(23):3095-3105

27 Kessler RC. Epidemiology of women and depression. J Affect Disord 2003;74(1):5-13

28 Whang W, Kubzansky LD, Kawachi I, et al. Depression and risk of sudden cardiac death and coronary heart disease in women: results from the Nurses' Health Study. J Am Coll Cardiol 2009;53(11):950-958

29 Smith SC Jr, Benjamin EJ, Bonow RO, et al; World Heart Federation and the Preventive Cardiovascular Nurses Association. AHA/ACCF secondary prevention and risk reduction therapy for patients with coronary and other atherosclerotic vascular disease: 2011 update: a guideline from the American Heart Association and American College of Cardiology Foundation. Circulation 2011;124(22):2458-2473 